\title{
A revision of the genus Kaszabister Mazur (Histeridae, Histerinae, Exosternini)
}

\author{
Nicolas Dégallier ${ }^{1, \dagger}$, Sławomir Mazur ${ }^{2, \ddagger}$, \\ Alexey K. Tishechkin ${ }^{3, \S}$, Michael S. Caterino ${ }^{3,1}$ \\ I 120 rue de Charonne, 75011 Paris, France 2 Katedra Ochrony Lasu i Ekologii, Warsaw University of Life \\ Sciences, Nowoursynowska 159/34, 02-776 Warszawa, Poland 3 Department of Invertebrate Zoology, Santa \\ Barbara Museum of Natural History, 2559 Puesta del Sol, Santa Barbara, California 93105 USA \\ † urn:lsid:zoobank.org:author:FD511028-C092-41C6-AF8C-08F32FADD16B \\ † urn:lsid:zoobank.org:author:73503FCF-629C-45E0-A077-6AF5830DB32C \\ § urn:lsid:zoobank.org:author:341C5592-E307-43B4-978C-066999A6C8B5 \\ | urn:lsid:zoobank.org:author:F687B1E2-A07D-4F28-B1F5-4A0DD17B6490 \\ Corresponding author: Michael Caterino (mcaterino@sbnature2.org) \\ Academic editor: Martin Fikácek | Received 17 April 2012 | Accepted 28 May 2012 | Published 4 June 2012 \\ urn:lsid:zoobank.org:pub:90769115-ED6E-4B4F-BCOC-24749E925EC8 \\ Citation: Dégallier N, Mazur S, Tishechkin AK, Caterino MS (2012) A revision of the genus Kaszabister Mazur \\ (Histeridae, Histerinae, Exosternini). ZooKeys 199: 71-89. doi: 10.3897/zookeys.199.3245
}

\begin{abstract}
We revise the four species of Kaszabister Mazur, 1972, one of which, Kaszabister barrigai sp. n., is described as new. The other species in the genus are K. rubellus (Erichson, 1834), K. ferrugineus (Kirsch, 1873 ) and $K$. carinatus (Lewis, 1888). The species are principally known from the subtropics of South America, with one in Central America. Lectotypes are designated for K. rubellus and $K$. ferrugineus, and a key is provided for all the species. Ants of the genus Solenopsis Westwood, mainly S. invicta Buren and S. saevissima (Smith), are documented as hosts of three of the four species.
\end{abstract}

\section{Keywords}

Histeridae, Exosternini, Kaszabister, myrmecophily, Solenopsis, Neotropical Region

\section{Introduction}

The genus Kaszabister Mazur, 1972, was initially described for a single species, now known as $K$. rubellus (Erichson, 1834), and assigned to the myrmecophilous and termitophilus subfamily Haeteriinae. Later, two other species originally described in other genera

Copyright Nicolas Dégallier et al. This is an open access article distributed under the terms of the Creative Commons Attribution License 3.0 (CC-BY), which permits unrestricted use, distribution, and reproduction in any medium, provided the original author and source are credited. 
(Epierus ferrugineus Kirsch, 1873, and Phelister carinatus Lewis, 1888) were moved here, and the entire genus was moved to Histerinae: Exosternini (Mazur 1997). This dynamic taxonomic history underscores the enigmatic nature of this genus, and its affinities within the tribe remain unclear. Similarly, little is known about the biology of these species, although it has become clear that they live as guests in the nests of fire ants of the genus Solenopsis Westwood. These ants are a major nuisance as a result of invasion into many tropical and subtropical climates (Hölldobler and Wilson 1990). It is therefore important to better understand the commensal predators that may play a role in controlling ant populations.

This paper represents the first installment of an ongoing revision of all the species of New World Exosternini. The fauna is large and complex, with the limits of most genera poorly understood. Kaszabister is among the more straightforward and clearly monophyletic groups, and preliminary analyses (Caterino et al. in prep) indicate that it lies outside any other named genus. Thus we are confident in retaining its status as a genus.

\section{Materials and methods}

The morphological terminology used is that defined by Wenzel and Dybas (1941), supplemented by Helava et al. (1985), Ôhara (1994) and Lawrence et al. (2011). Following histerid conventions, total body length is measured from the anterior margin of the pronotum to the posterior margin of the elytra (to exclude preservation variability in head and pygidial extension), while width is taken at the widest point, generally near the elytral humeri. Type material of all valid species was examined by one or more of the authors. Photographic imaging was done using a Visionary Digital's 'Passport' portable imaging system, which incorporates a Canon D7 with MP-E $65 \mathrm{~mm}$ 1-5X macro zoom lens. Images were stacked using Helicon Focus software. SEM imaging was done on a Zeiss EVO 40 scope, with most specimens sputter coated with gold. Photographs of all type specimens are available through the Encyclopedia of Life (www.eol.org).

Specimens from the following institutions were utilized:

BMNH The Natural History Museum, London, UK

CHAT The Alexey Tishechkin Collection, Santa Barbara, USA

CHND The Nicolas Degallier Collection, Paris, France

CHPK The Piet Kanaar Collection, Leiden, The Netherlands

CHSM The Slawomir Mazur Collection, Warsaw, Poland

DBIA University of Brasilia, Distrito Federal, Brazil

EMEC The Essig Museum of Entomology, Berkeley, USA

FMNH The Field Museum, Chicago, USA

FSCA Florida State Collection of Arthropods, Gainesville, USA

HNHM Hungarian Natural History Museum, Budapest, Hungary

INBI Instituto Nacional de Biodiversidad, San Jose, Costa Rica 
$\begin{array}{ll}\text { MACN } & \begin{array}{l}\text { Museo de Ciencias Naturales "Bernardino Rivadavia", Buenos Aires, } \\ \text { Argentina }\end{array} \\ \text { MNHN } & \text { Museum National d'Histoire Naturelle, Paris, France } \\ \text { NMNH } & \text { National Museum of Natural History, Washington, USA } \\ \text { SMTD } & \text { Staatlichen Museum für Tierkunde, Dresden, Germany } \\ \text { ZHMB } & \text { Museum für Naturkunde, Berlin, Germany }\end{array}$

\section{Taxonomy}

Genus Kaszabister Mazur, 1972

http://species-id.net/wiki/Kaszabister

Kaszabister Mazur, 1972: 189.

Type species. Kaszabister mahunkai Mazur, 1972 (now regarded as a junior synonym of $K$. rubellus (Erichson, 1834)), original designation.

Diagnosis. Kaszabister can be easily separated from other Neotropical Exosternini by its strongly carinate frontal stria (Fig. 3); epipleural, subhumeral, and dorsal elytral striae 1 apically carinate and convergent to posterolateral corner (Fig. 1B, 2A); and narrow, edentate meso- and metatibiae which bear only a few small spines (Figs 1B, $2 \mathrm{~A}, 4)$. The narrowly depressed lateral pronotal margin is also rare in other genera (Figs 1A, 2B).

Description. Body length $1.7-2.3 \mathrm{~mm}$, width $1.3-1.7 \mathrm{~mm}$, oval or oblong, more or less convex, reddish brown, glabrous. Head: Frons bordered by a prominent, moderately to strongly carinate frontal stria; antennae inserted under the rim of the frons in front of eyes; antennal scape slightly setose; antennal club oval, tomentose, lacking sutures or annuli, with small oval subapical sensoria on upper and lower surfaces; epistoma flat to convex, bordered by striae or carinae; labrum short, broad, rounded at sides and emarginate at middle; mandibles with strong furrows along lower outer margins and very weak subapical teeth on incisor edge; gena setose and weakly depressed; gular sutures impressed; submentum with numerous fringed setae, projecting slightly between maxillar bases; mentum about one-fourth broader than long, sides rounded, tapering apically, margin faintly emarginate; palpi relatively short, with truncate apices. Pronotum: pronotum widest at base, sides rounded, anterior angles acute; prescutellar impression absent; gland openings annulate, situated about one-third from anterior margin, behind inner edge of eye on each side; with 3 pores along each side; marginal stria complete, continuous with anterior marginal stria; lateral stria absent. Elytra: Dorsal striae of elytra simple or carinate, variously abbreviated; dorsal stria 1, subhumeral striae, and epipleural stria carinate and convergent apically. Prosternum: Antennal cavities of the prosternum visible in ventral view, located in the anterior angles of pronotum; prosternal lobe short, broad, reaching hypomeron laterally, with marginal stria at least medially; base of prosternal keel weakly emarginate; with complete carinate striae diverging 
anterad and posterad, not joined. Mesoventrite: Disk flat, weakly projecting at middle, with complete marginal stria; mesometaventral stria present, angulate forward onto mesoventral disk. Metaventrite: Metaventral disk with postcoxal and lateral striae, both extending laterad toward metepisternum. Abdomen: Propygidium short, moderately convex, with annulate gland openings in anterolateral corners; pygidium lacking apical stria; abdominal ventrite 1 with one or two lateral striae; ventrites $2-5$ with or without posterior marginal striae. Legs: Protrochanter with seta; protibia lacking teeth, but with 8-10 stout marginal spines; protibial spurs short, strong; protarsus with fine ventral spines, pretarsal claws simple and equal; meso- and metatrochanters lacking setae; mesoand metatibiae nearly parallel-sided, the former with few weak marginal spines; mesoand metatarsomeres with single pair of apicoventral setae. Male: Eighth tergite with accessory sclerites, shallowly narrowly incised at subtruncate apex, with basal membrane attachment distad basal emargination; ventral apodemes of $8^{\text {th }}$ tergite broadly rounded, not meeting at midline; $8^{\text {th }}$ sternite approximately parallel-sided, halves not joined along midline, with apical guides gradually more strongly elevated toward apices; 9th tergite with median emargination deep, ventral apodemes situated just behind midpoint, strongly toothed; spiculum gastrale ( $9^{\text {th }}$ sternite) narrowed in distal two-thirds, with thin apical arms and short median apical flanges; halves of $10^{\text {th }}$ tergite well developed, separated along midline. Female: Eighth tergite forming a single, apically emarginate plate; $8^{\text {th }}$ sternite divided into two lateral plates, with thin, separate basal baculi which are articulated with the disk of S8; $9^{\text {th }}$ sternite present, elongate, connected to apex of S8; tenth tergite present, without basal apodemes; valvifers elongate, enlarged basally; coxites with two strong and one weak inner tooth; gonostyle present, free, setose; bursa copulatrix small; spermatheca short, sclerotized, forming a ventral concave disk over oviduct; spermathecal gland attached at base of spermatheca, elongate, gradually expanded to apex.

Distribution. The distribution of the species of this genus is interestingly discontinuous, with three species concentrated in subtropical South America, and a single species from Central America, with few records from the northern half of South America.

\section{Key to species}

1 Postmetacoxal striae of the first ventrite joined in an arch along the anterior margin (Fig. 4A); lateral metaventral stria terminating about one-third metaventral length behind the mesometaventral suture (Fig. 4A); frontal stria descending onto epistoma only, without stria across anterior margin of frons (Fig. 3A); southern Brazil, Paraguay, Argentina...Kaszabister barrigai sp. n.

- Postmetacoxal striae not joined in an anterior arc; lateral metaventral stria reaching (Fig. 4B, D) or nearly reaching (Fig. 4C) mesometaventral suture; frontal stria variable

Abdominal ventrites 2-5 lacking posterior marginal stria (Fig. 4D); southern Mexico to Costa Rica. Kaszabister carinatus (Lewis, 1888) 
3 Frontal stria complete and evenly arcuate across frons (Fig. 3B); epistoma convex; lateral stria of metaventrite reaching mesometaventral suture (Fig. 4B); Peru, Brazil, Uruguay, Argentina .....Kaszabister ferrugineus (Kirsch, 1873) - $\quad$ Frontal stria not evenly arcuate, descending onto epistoma as a weak marginal carina (Fig. 3C); epistoma depressed; lateral stria of metaventrite abbreviated about one-fourth behind mesometaventral suture (Fig. 4C); southern Brazil, Uruguay, Argentina..... Kaszabister rubellus (Erichson, 1834)

\section{Kaszabister barrigai sp. n.}

urn:Isid:zoobank.org:act:03F0FB0E-8486-4E3A-A744-A242165F2C9C http://species-id.net/wiki/Kaszabister_barrigai

Figs 1, 2A, 3A, 4A, 6A-B, 7 (map)

Type material. Holotype: male: "BRAZIL: State of Mato Grosso, Rondonópolis Co., Rondonópolis" / "R. Beasley, 14.VII.72, Floated from ant nest \#169" / "Caterino/ Tishechkin Exosternini Voucher EXO-00255 / HOLOTYPE Kaszabister barrigai Dégallier et al. des. 2012"; deposited in FSCA. Paratypes (109): ARGENTINA: Cordoba: Alta Gracia, La Granja, Sierras de Córdoba, 10.i.1925 (1: MACN); same locality and date, "debajo de uma piedra en el medio de las Solenopsis" (1: MACN); ARGENTINA: "on grapes (fruit) from Argentina, Kennedy, N.Y., 22.iv.1935” (1: NMNH); BRAZIL: Mato Grosso: Mato Grosso, Buriti, 20.vii.1972, floated from ant nest (3: FSCA); Mato Grosso, Cáceres, 5.vii.1972, floated from ant nest (6: FSCA); Mato Grosso, Cuiabá, Parque de Exposição, 30.v.1972, floated from ant nest (7: FSCA); same label data but 1.vi.1972 (12: FSCA); same label data but 6.vi.1972 (5: FSCA); same label data but 7.vi.1972 (3: FSCA); same label data but 13.vi.1972 (1: FSCA); same label data but 14.vi.1972 (4: FSCA); same label data but 14.vi.1972 (6: FSCA); same label data but 20.vi.1972 (13: FSCA); same label data but 22.vi.1972 (1: FSCA); Mato Grosso, Fazenda of Augusto Miller, $10 \mathrm{~km} \mathrm{~N} \mathrm{Chapada} \mathrm{dos}$ Guimarães, 21.v.1972, floated from ant nest (1: FSCA); Mato Grosso, Mato Grosso Co., 25.vii.1972, floated from ant nest (6: FSCA); Mato Grosso, Poconé, 23.iv.1972, floated from ant nest (9: FSCA); Mato Grosso, Pontes e Lacerda, 3.vii.1972, floated from ant nest (1: FSCA); 12 specimens from Mato Grosso, Rondonópolis, 14.vii.1972, floated from ant nest (12: FSCA); same label data but 15.vii.1972 (2: FSCA); Mato Grosso, Rosario Oeste, 13.vii.1972, floated from ant nest (3: FSCA). Sáo Paulo: São Paulo, São Paulo, xii.1972, from fire ant nests (6: FSCA) ; São Paulo, Vargem Grande [do Sul], 1.xii.1972 (1: FMNH, 2: NMNH); São Paulo, Vargem Grande do Sul, 17.iii.1972, nest of Solenopsis saevissima gp. (1: FMNH); São Paulo, Varzea Grande, 9.ii.1972 (1: FSCA); same label data but 1.xii.1972 (2: FSCA). PARAGUAY: San Pedro: San Pedro, Cororó, x.1979 (1: CHND).

Diagnostic description. Length $1.9-2.3 \mathrm{~mm}$; width $1.5-1.7 \mathrm{~mm}$; Frontal stria descending onto epistoma as a strong carina, epistoma strongly depressed, depression broader than in K. rubellus; fourth dorsal elytral stria present in apical half to twothirds; inner subhumeral elytral stria present in apical two-thirds; fifth elytral stria generally absent; sutural stria present in apical half; elytral ground punctures denser and 


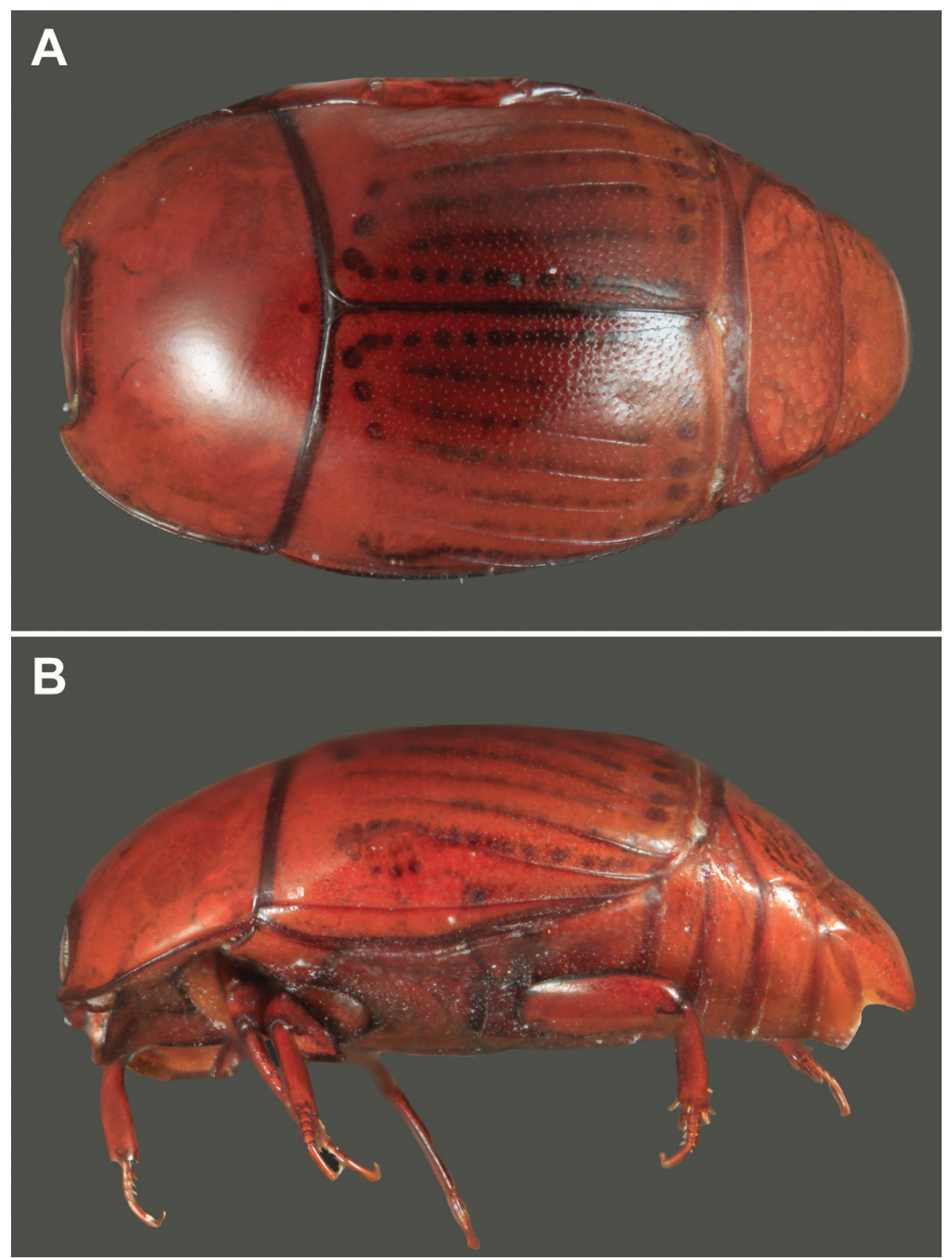

Figure I. Habitus photos of Kaszabister barrigai sp. n. A Dorsal B Lateral. 

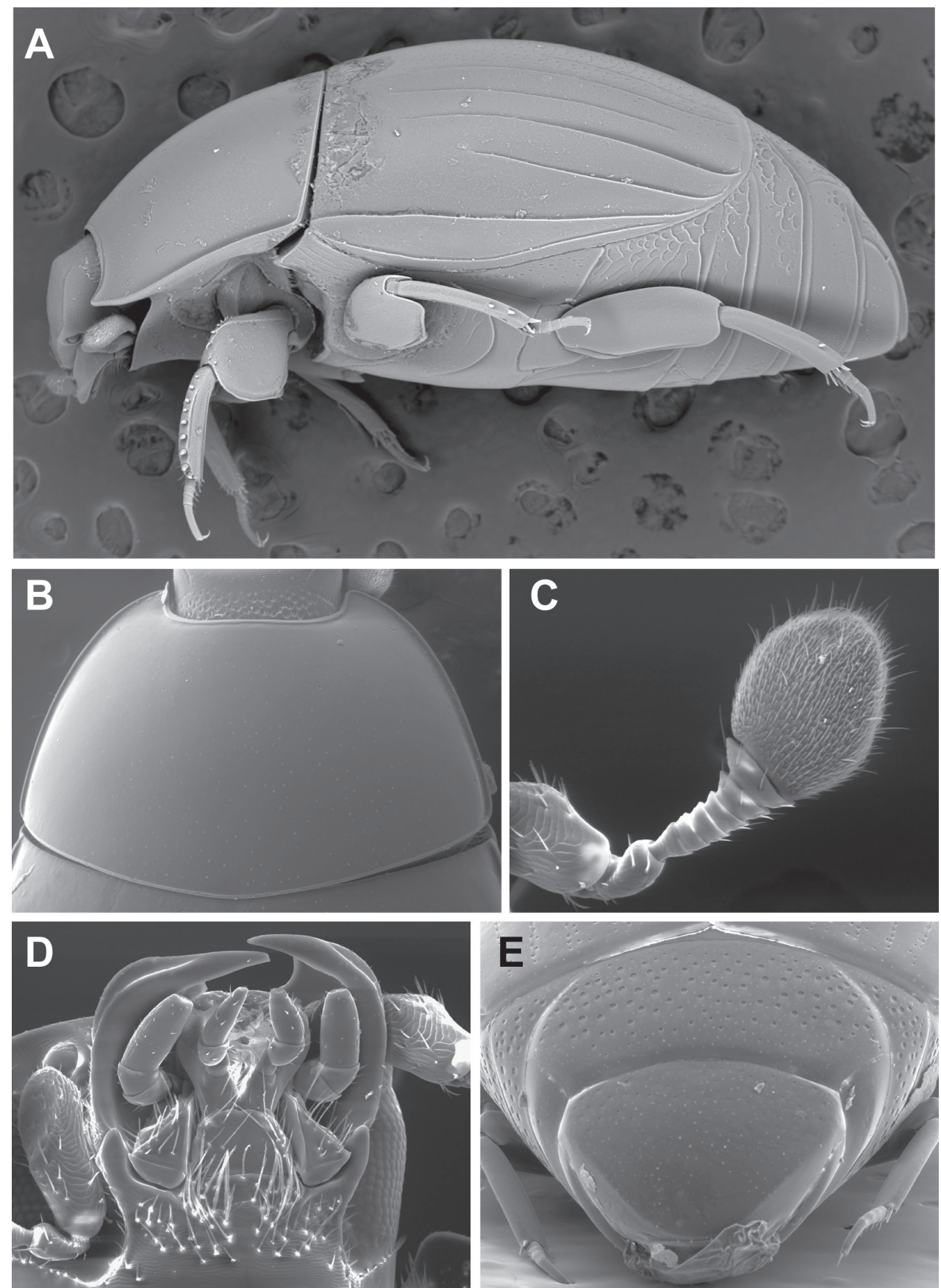

Figure 2. Generic characters of Kaszabister. A Lateral habitus of K. barrigai showing carinate and convergent dorsolateral elytral striae B Pronotum of $K$. carinatus C Antenna of $K$. carinatus D Mouthparts of $K$. carinatus $\mathbf{E}$ Propygidium and pygidium of $K$. carinatus. 

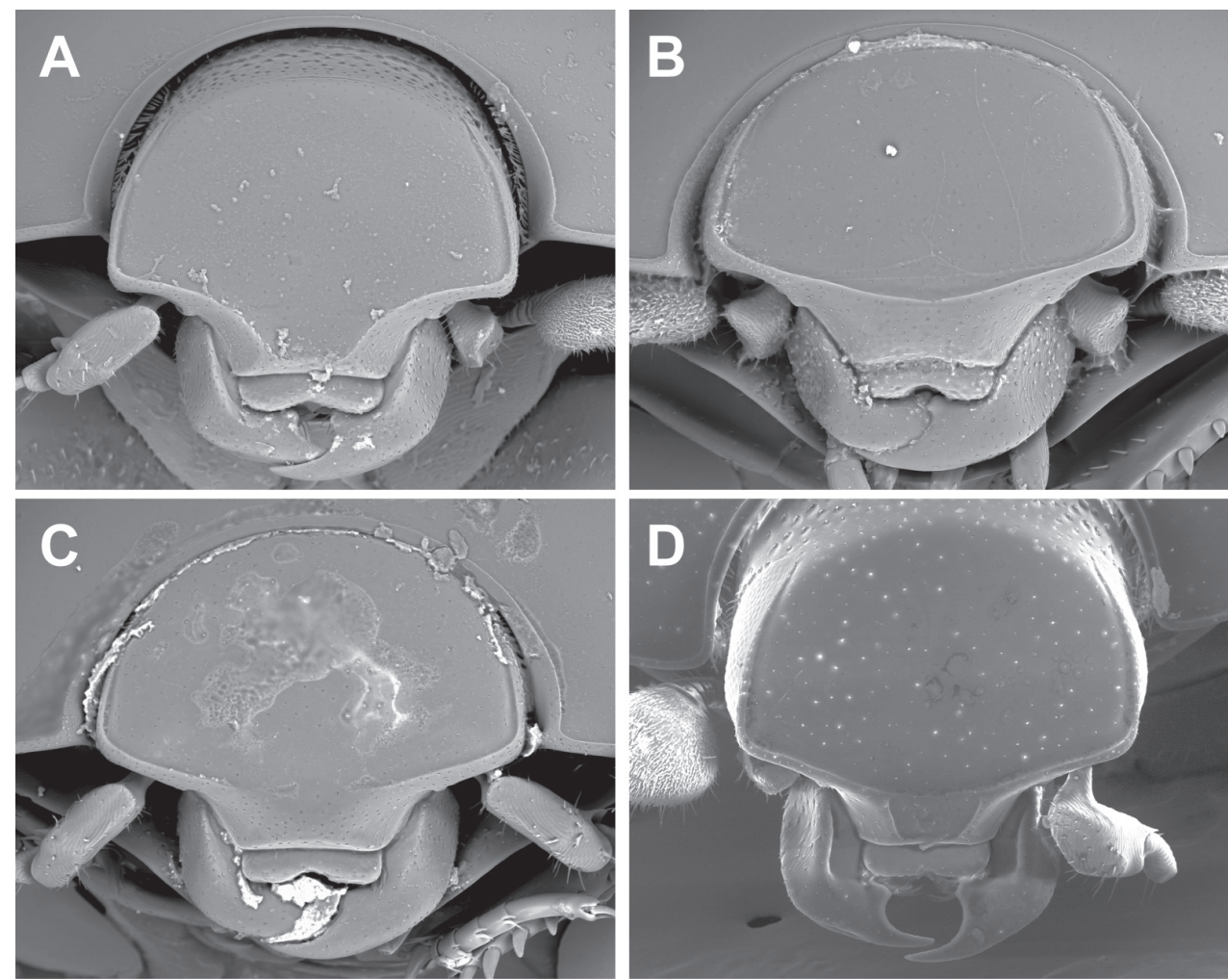

Figure 3. Anterior view of head. A Kaszabister barrigai B $K$. ferrugineus $\mathbf{C} K$. rubellus $\mathbf{D} K$. carinatus.

more uniformly distributed; mesometaventral stria arched forward to between one-half to one-third from anterior mesoventral margin; lateral metaventral stria strongly abbreviated mediad, ending about one-third from mesometaventral margin; inner postmetacoxal striae forming a complete, narrow arc across anterior margin of abdominal ventrite 1; abdominal ventrites 2-4 with apical marginal stria. Male: Aedeagus narrow, elongate, swollen toward base, flattened apically in lateral view.

Distribution. Known principally from the Brazilian states of Mato Grosso and São Paulo, with one record each from Argentina and Paraguay, and a single specimen found in an Argentinian grape shipment at Kennedy Airport, New York, USA.

Biology. While the majority of the type specimens say merely that they were collected from 'ant nest', there is little doubt that the hosts were Solenopsis Westwood, probably Solenopsis invicta Buren, 1972, the focus of the work of collectors Lennartz and Whitcomb (Allen et al. 1974, Buren et al. 1974). Other records specify 'fire ants', Solenopsis sp., and 'Solenopsis saevissima group' as hosts.

Etymology. This species is named for the notable Chilean collector Juan Enrique Barriga-Tuñón, who provided us with one of the first known examples of the species.

Remarks. Specimens labelled as 'São Paulo, Varzea Grande' most probably came from Vargem Grande do Sul in the same state. We were not able to find any place 

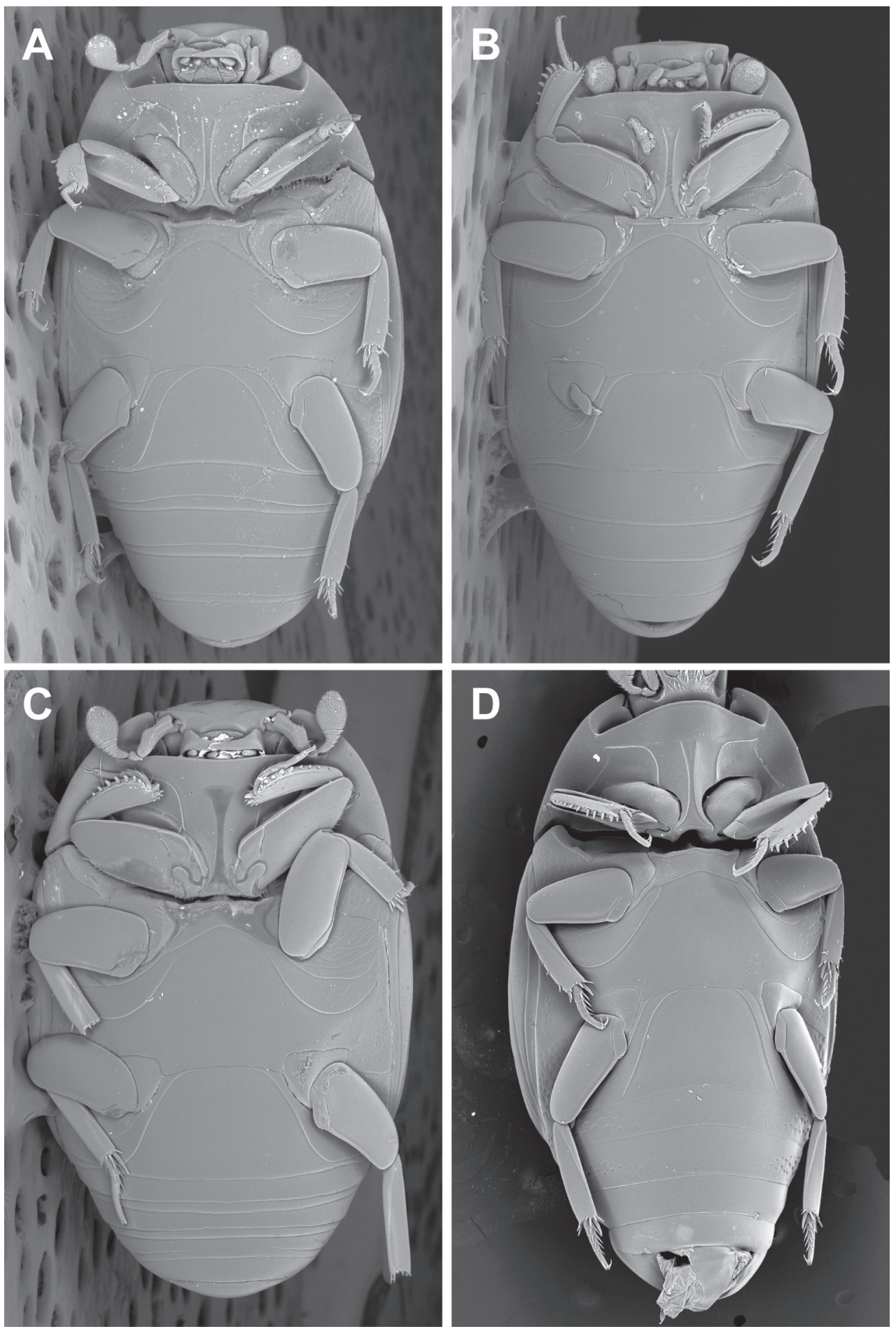

Figure 4. Ventral habitus. A Kaszabister barrigai B $K$. ferrugineus C $K$. rubellus D $K$. carinatus. 
called Varzea Grande in São Paulo. On the other hand, there is a town of this name that is a part of greater Cuiabá, the capital of Mato Grosso, where the fire ant researchers who collected specimens from Mato Grosso and São Paulo were apparently based. But given that we have seen specimens collected on the same day, 1.xii.1972, in 'São Paulo, Vargem Grande' (3) and 'Sáo Paulo, Varzea Grande' (1), we suspect confusion and mislabeling for the latter locality.

\section{Kaszabister carinatus (Lewis, 1888)}

http://species-id.net/wiki/Kaszabister_carinatus

Figs 2B-E, 3D, 4D, 6G-H, 9 (map)

Phelister carinatus Lewis, 1888: 194.

Kaszabister carinatus: Mazur (1997: 31).

Type material. Holotype ("one example"; Lewis, 1888) of undetermined sex: "Cerro Zunil, 4-5000 ft. Champion”/ "Sp. figured." / " B.C.A., Col.,II,(1). Phelister" / "Phelister carinatus Lewis Type" / "Type" [red circle] / "HOLOTYPE N. Dégallier 2007"; BMNH.

Other material: MEXICO: Chiapas: Mpio. Trinitaria, Lagunas de Montebello, 4-31.viii.1991, FIT (1: FMNH); Michoacan: San Jose Purua, vi.1965 (1: CHSM); 'Mexico, A.G.' (1: BMNH). COSTA RICA: Alajuela: RNVS Caño Negro, 18-30. xi.1992, 5-28.ii.1995 (2: INBI); Guanacaste: Est. Los Almendros, 4-16.ix.1994 (1, INBI); Heredia: Est. Biol. La Selva, $2.5 \mathrm{~km} \mathrm{~S}$ Puerto Viejo, 24.vi.2003, at light (1: EMEC); Limón: Cerro Cocori, iii.1993, iv.1993, v.1993 (3: INBI); Rio Sardinas, RNFS Barra del Colorado, 6-14.iv. 1994 (1: INBI); Sect. Cerales de la Rita, 3 km N. del Puente Rio Suerte, Ruta Puerto Lindo, iii.1996 (1: INBI); Reventazon Evene, Hamburg Farm, 2.i.1932 (1: NMNH); P.N. Tortuguero, Est. Cuatro Esquinas, ix.1992 (1: INBI); Puntarenas: P.N. Corcovado, Est. Sirena, Send. Espavel, 19.iv.2001 (1: INBI); San Jose: San Jose, ix.1935 (1: CHND).

Diagnosis. Frontal stria continuous across front and connected to epistomal striae, epistoma flat; fourth dorsal elytral stria complete and arched to suture; inner subhumeral elytral stria usually present only in apical half; fifth and sutural elytral striae weak, often just series of punctures, but generally present in apical one-third; elytral ground punctures sparser and markedly reduced laterad fourth elytral stria; mesometaventral stria arched forward to about one-half from mesoventral margin; lateral metaventral stria reaching mesometaventral margin, but distinctly mediad junction of mesometaventral and postmesocoxal striae; inner postmetacoxal striae somewhat variable, but never forming a complete arc across anterior margin of abdominal ventrite 1 ; abdominal ventrites 2-4 completely lacking apical marginal stria; aedeagus of moderate width, more strongly tapered basally than apically, with ventral curvature only marked nearer apex.

Distribution. This species is restricted to Central America, from southern Mexico to Costa Rica.

Remarks. No specimens bear any host data. 
Kaszabister ferrugineus (Kirsch, 1873)

http://species-id.net/wiki/Kaszabister_ferrugineus

Figs 3B, 4B, 5, 6C-D, 8 (map)

Epierus ferrugineus Kirsch, 1873: 137.

Phelister ferrugineus: Lewis (1905: 47).

Kaszabister ferrugineus: Mazur (1997: 31).

Phelister marginicollis Lewis, in litteris: Bruch (1914: 309).

Phelister marginicollis Bruch, 1914 (sic!): Mazur (1997: 31), as nomen nudum.

Type material. Lectotype, herein designated for the purposes of establishing a unique and unambiguous type, as the original description omitted any indication of number of specimens studied: of undetermined sex: [Peru:] "Pozuzu, M. Kirsch" / "Epierus ferrugineus" / "Staatl. Museum für Tierkunde, Dresden" / "LECTOTYPE Dégallier \& Mazur, 2007" / "Kaszabister ferrugineus (Kirsch, 1873); SMTD.

Other material. ARGENTINA: Buenos Aires: Buenos Aires, 30.vii.1917, 9.vii.1923, 5.viii.1923 (4: MACN, NMNH); La Plata, viii.1912, nest of Solenopsis saevissima (2: NMNH); Rosas - F. C. Sud (7: NMNH); San Fernando, viii.1960 (1: NMNH). Mendoza: Mendoza, 20.x.1907 (1: ZMHB). BRAZIL: 'Bahia' (4: ZMHB). Distrito Federal: Brasilia, IBGE Ecological Reserve, 24.vi.1987, 13.v.1987, 7.vi.1987, 20.i.1998 (6: CIZUB, CHAT, CHND). Mato Grosso: Arenapolis, 22.viii.1972 (23: FSCA); Cáceres, 5.vii.1972 (1: FSCA); Cuiabá, 19.vi.1972 (1: FSCA); Mato Grosso Co., 25.vii.1972 (1: FSCA); Poconé, 23.iv.1972 (1: FSCA); Rondonópolis, 14-15. vii.1972 (3: FSCA); Rosario Oeste, 14.vii.1972 (1: FSCA). Pará: Belém, 2.vi.1985, flotation of the Solenopsis saevissima nest (identified by W. L. Overal) (1: CHND). Rondônia: Guajará Mirim, 1.ix.1972 (1: FSCA). São Paulo: São Simão, Usina Sta. Clara, 5.ix.1973 (3: FMNH). URUGUAY: Artigas: Ruta 30, km 45, 12.xii.1962, nest of Solenopsis saevissima (1: CHSM).

Diagnosis. Frontal stria straight to evenly arcuate across front, not descending onto epistoma; fourth dorsal elytral stria complete and arched to suture; inner subhumeral elytral stria present in apical two-thirds; fifth elytral stria variable, from absent to present in apical one-half; sutural stria present in apical half; elytral ground punctures sparser and markedly reduced laterad fourth elytral stria; mesometaventral stria arched forward to about one-third from mesoventral margin; lateral metaventral stria reaching mesometaventral margin, nearly or fully meeting mesometaventral stria and postmesocoxal stria; inner postmetacoxal striae not forming a complete arc across anterior margin of abdominal ventrite 1, ending close to metacoxa; abdominal ventrites 2-4 with apical marginal stria; aedeagus rather short, parallel-sided, with apex subtruncate.

Distribution. Known from Argentina (Mendoza, Buenos Aires), Brazil (Bahia, Distrito Federal, Mato Grosso, Pará, Rondônia and São Paulo), Peru (Huanuco) and Uruguay (Artigas).

Biology. As for $K$. barrigai, many records of $K$. ferrugineus from 'ant nests' almost certainly refer to Solenopsis invicta as host, while a few other labels specify S. saevis- 


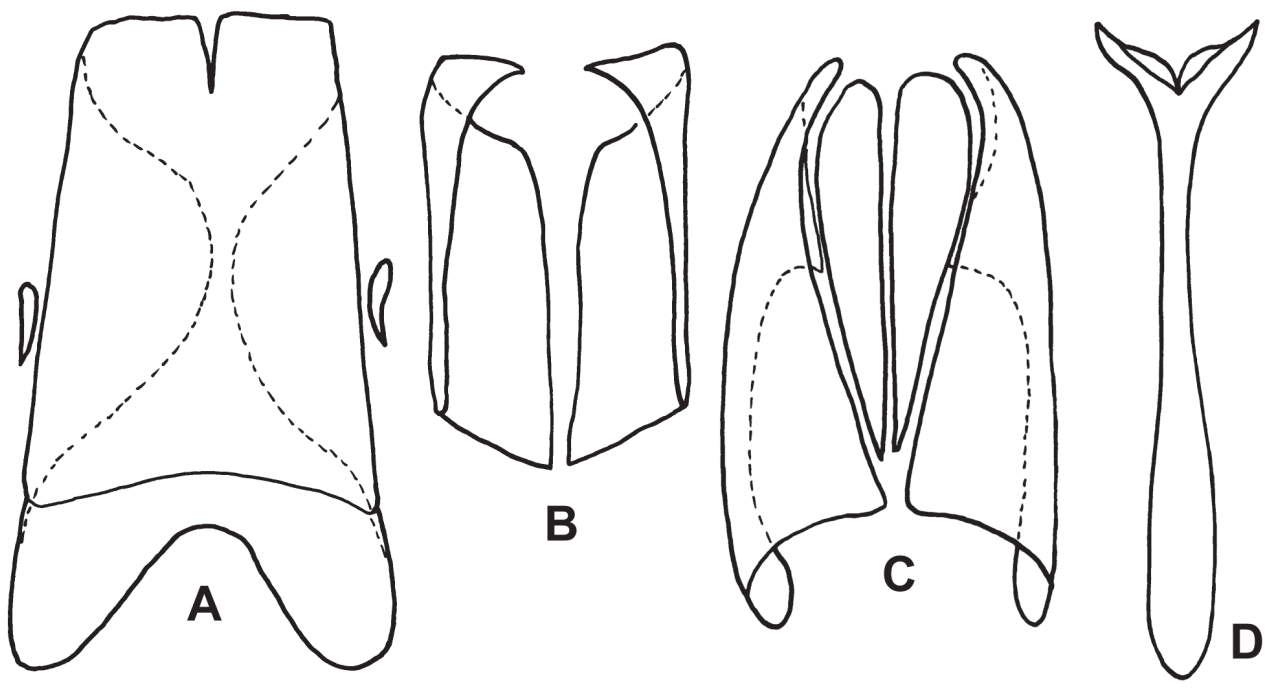

Figure 5. Male genitalia of Kaszabister ferrugineus. A $8^{\text {th }}$ tergite (with accessory sclerites) B $8^{\text {th }}$ sternite C $9^{\text {th }}$ and $10^{\text {th }}$ tergites $\mathbf{D}$ Spiculum gastrale ( $=9^{\text {th }}$ sternite).

sima (Smith). One specimen from Bahia in the Lewis collection bears a label "with an Aphaenogaster" (Formicidae). However, no host specimen is present for verification.

Remarks. Mazur (1997) cites "Phelister marginicollis Bruch, 1914" as "nom. nud. - syn. nov., Wenzel in litt.". Bruch (1914: 309) cites this as "Phelister marginicollis Lew. in litteris". This appears to have been a species that Lewis intended to describe based on Bruch's specimens, and he indicated such to Bruch. Specimens labeled "P. marginicollis Lewis" are present in the BMNH and NMNH. However, for whatever reason, the species was never formally published, so it is indeed a nomen nudum. In Bruch's later works (e.g., 1935) he apparently realized that the species was not properly described and omitted it from his catalog.

Kaszabister rubellus (Erichson, 1834)

http://species-id.net/wiki/Kaszabister_rubellus

Figs 3C, 4C, 6E-F, 7 (map)

Epierus rubellus Erichson, 1834: 163.

Kaszabister rubellus: Mazur (1984: 304).

Kaszabister mahunkai Mazur, 1972: 189. Synonymized by Mazur (1984).

Type material. Epierus rubellus: Lectotype herein designated for the purposes of establishing a unique and unambiguous type, as the original description omitted any indication of number of specimens studied: of undetermined sex: "rubellus Er., Carap[ava]. Sellow" / "48997" / "Zool. Mus. Berlin" / "Kaszabister rubellus (Erich- 

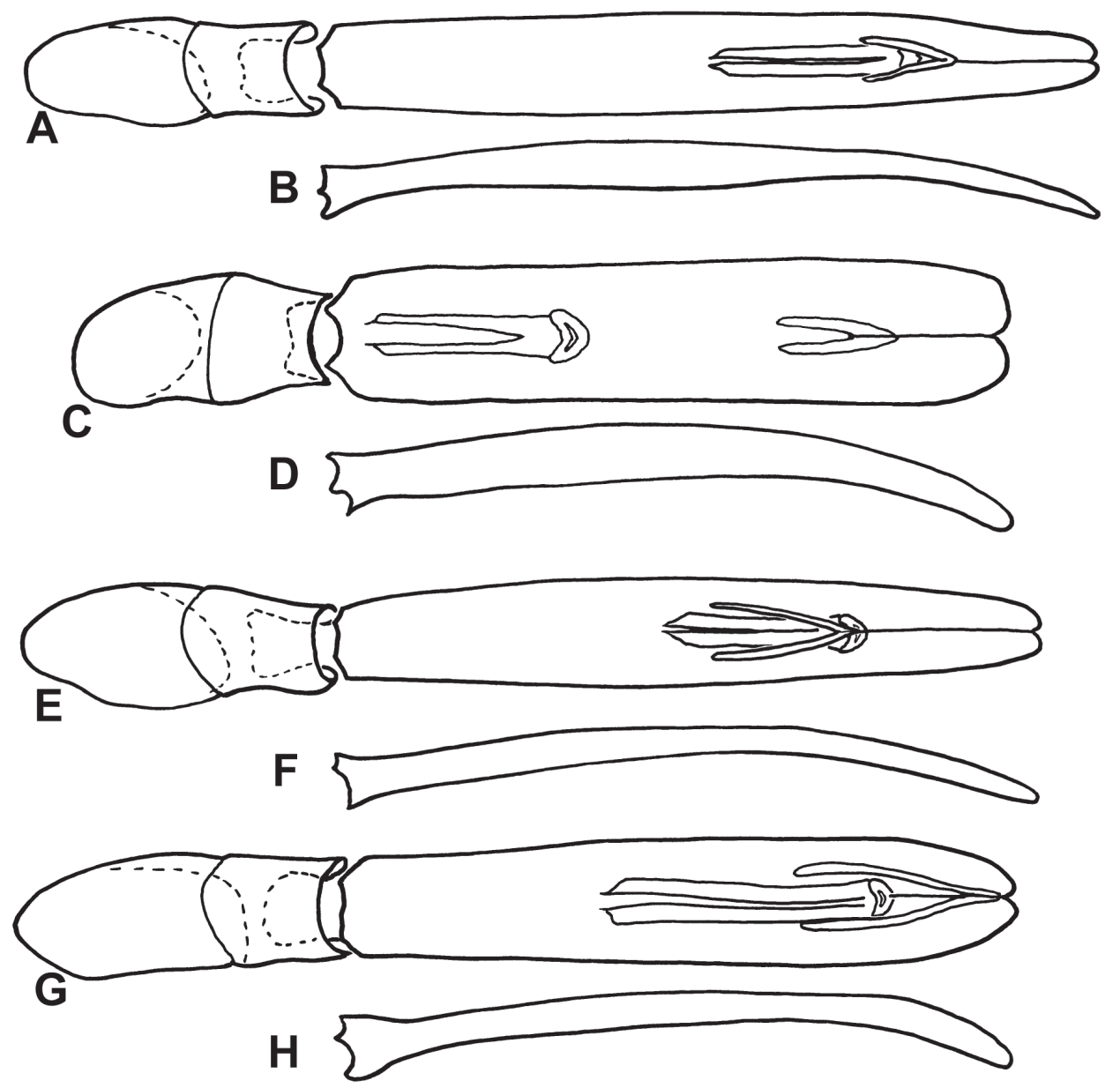

Figure 6. Male genitalia of Kaszabister. A Dorsal view of aedeagus of $K$. barrigai B Lateral view of aedeagus of $K$. barrigai $\mathbf{C}$ Dorsal view of aedeagus of $K$. ferrugineus $\mathbf{D}$ Lateral view of aedeagus of $K$. ferrugineus $\mathbf{E}$ Dorsal view of aedeagus of $K$. rubellus $\mathbf{F}$ Lateral view of aedeagus of $K$. rubellus $\mathbf{G}$ Dorsal view of aedeagus of $K$. carinatus $\mathbf{H}$ Lateral view of aedeagus of $K$. carinatus.

son) LECTOTYPE N. DEGALLIER"; ZMHB. Kaszabister mabunkai: holotype: "Hungarian Soil-Zool. Exp., ARGENTINA: Prov. Córdoba, Fanti, Sierra de Córdoba, 11.I.1966" / "Nr. P-B.325 leg.Mahunka" / "Holotype 1972. Kaszabister mahunkai Mazur." / "HOLOTYPUS" / "Compared with META-Types Epierus rubellus Er., R. L. Wenzel '73" / "Kaszabister rubellus (Er.) (= mahunkai Mazur), RLW '73” (HNHM).

Other material. ARGENTINA: Buenos Aires: Balcarce, iv.1957 (1: NMNH); Rosas - F.C. Sud, with Solenopsis (6: NMNH). BRAZIL: Paraná: Rio Negro, with Solenopsis (1: BMNH); Rio Grande do Sul: Vallée de la Ferradura, Canela, 20.x.1989, from nest of Solenopsis sp. (1: CHND); Santa Catarina: Nova Teutonia, v.1937 (1: FMNH); 31.x.1948, with Solenopsis (2: FMNH); 2-3.xi.1948, with Solenopsis (2: FMNH); $11-$ 


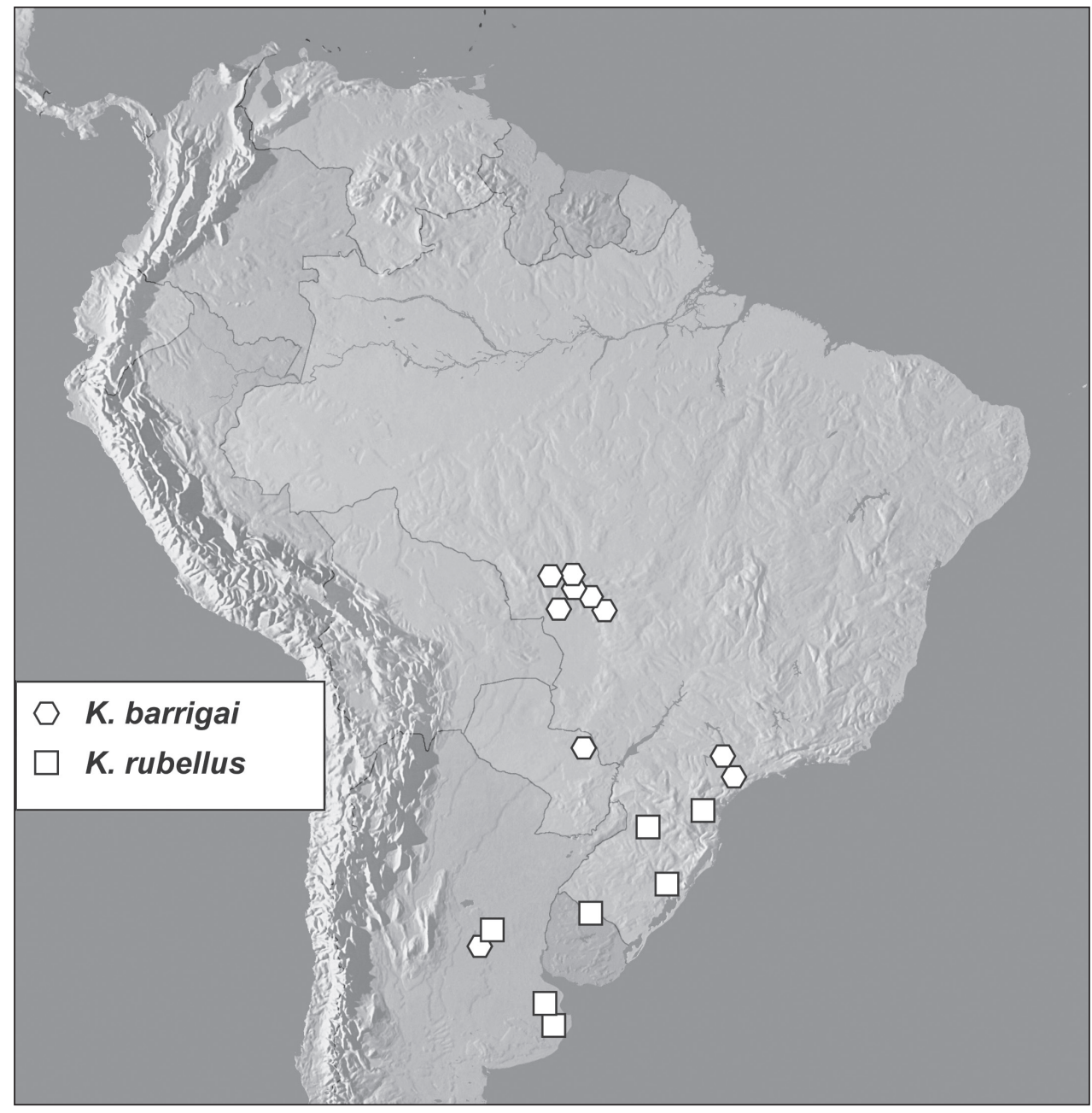

Figure 7. Map showing distributional records of Kaszabister barrigai and K. rubellus.

14.xi.1948, with Solenopsis (2: FMNH); xii.1948 (1: FMNH); 6.vi.1950 (1: FMNH); 6.vii.1950 (1: FMNH); 2.viii.1950, with Solenopsis (4: FMNH); 26.viii.1950 (5: FMNH); 28.viii.1950, with Solenopsis (4: FMNH); 1.ix.1950 (1: FMNH); 3.ix.1950, with Solenopsis (1: FMNH); 6.ix.1950, with Solenopsis (2: FMNH); 7.ix.1950, with Solenopsis (1: FMNH); 18.ix.1950 (1: FMNH); 20.ix.1950, with Solenopsis (1: FMNH); 23.ix.1950 (1: FMNH); 4-5.x.1950, with Solenopsis (2: FMNH); 21.vii.1951 (1: FMNH); 24.vii.1951, with Solenopsis (1: FMNH); 31.vii.1951, with Solenopsis (8: FMNH); 17.viii.1951 (4: FMNH); 22.viii.1951 (1: FMNH); 5.ix.1951 (1: FMNH); 4.x.1951 (4: FMNH); 6-30.viii.1951, with Solenopsis (5: FMNH); 10.iv.1952, with Solenopsis (1: FMNH); 18.iv.1952, with Solenopsis (3: FMNH); 10.v.1952, with Solenopsis (1: FMNH); 10.v.1952, with Solenopsis (FMNH); 30.vii.1952, with Solenopsis (5: CHPK, CHSM, FMNH); 3.viii.1952, with Solenopsis (1: FMNH); 7.viii.1952, 


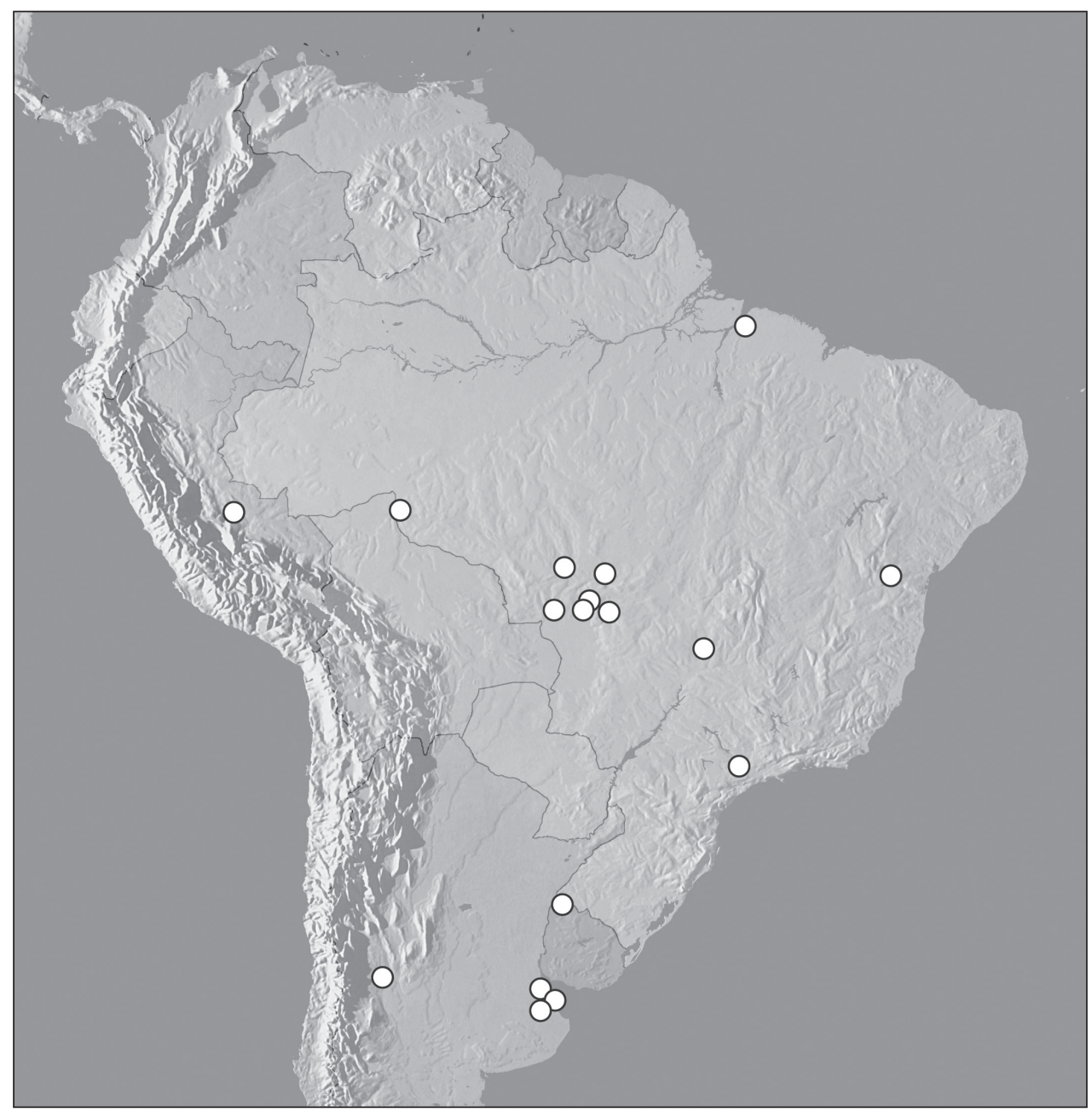

Figure 8. Map showing distributional records of Kaszabister ferrugineus.

with Solenopsis (2: FMNH); 15.viii.1952 (1: FMNH); viii.1952, with Solenopsis (48: FMNH); ix.1952 (1: FMNH); vi.1954 (2: CHSM); vii.1954, (2: CHSM); xi.1956 (1: FMNH); 'Bresil' (1: MNHN). URUGUAY: Rivera: Rivera, Escuela Agraria, 18.ii.1962, nest of Acromyrmex lundii (Guérin-Méneville) (1: FMNH).

Diagnosis. Frontal stria descending onto epistoma as a weak carina, epistoma moderately depressed, depression narrower than in $K$. barrigai; fourth dorsal elytral stria present in apical half to two-thirds; inner subhumeral elytral stria present in apical two-thirds; fifth and sutural elytral striae strongly reduced or absent; elytral ground punctures sparser and markedly reduced laterad fourth elytral stria; mesometaventral stria somewhat variable, arched forward to one-half to one-third from mesoventral margin; lateral metaventral stria weakly abbreviated mediad, ending about one-fourth to one-fifth metaventral length from mesometaventral margin, mesometaventral stria 


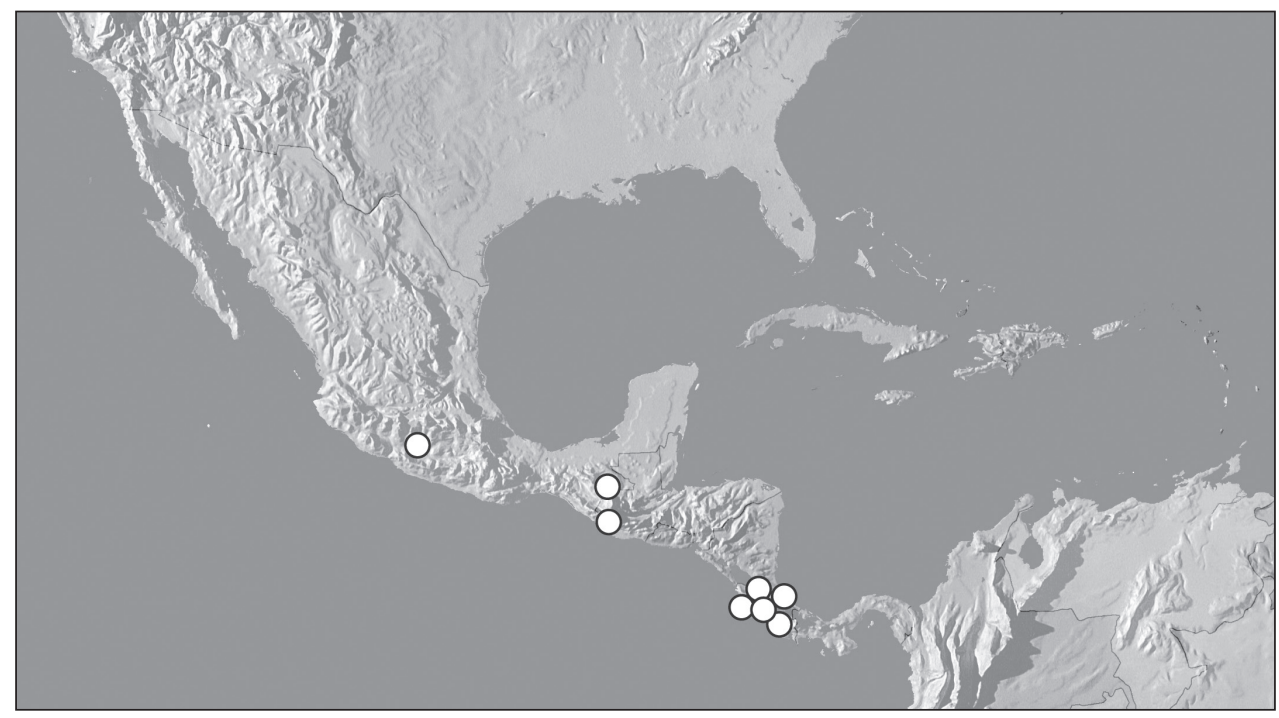

Figure 9. Map showing distributional records of Kaszabister carinatus.

continuous with postmesocoxal stria; inner postmetacoxal striae nearly forming a complete arc across anterior margin of abdominal ventrite 1 (though often evanescent at very middle), this arc broader (closer to coxae) than in $K$. barrigai; abdominal ventrites $2-4$ with apical marginal stria; aedeagus narrow, approximately evenly tapered basally and apically; flatter (in lateral view) than in other species.

Distribution. Known from Brazil (Paraná, Rio Grande do Sul, Santa Catarina), Argentina (Buenos Aires, Córdoba), Uruguay (Rivera).

Biology. Most specimens from Santa Catarina bear labels indicating collection with unspecified Solenopsis. The singleton from Uruguay indicates collection from a nest of Acromyrmex lundii.

Remarks. The synonymy of K. mahunkai Mazur with Epierus rubellus Erichson was originally designated by Mazur (1984) (citing "Wenzel, in litt."). We have not studied the type of $K$. mahunkai first-hand, but Ottó Merkl of the HNHM very kindly compared the type specimen with our descriptions, keys and figures, and had no doubt that the synonymy is valid. His study also confirmed that Wenzel had compared types of $K$. mahunkai and E. rubellus side-by-side in coming to his original conclusion that the two were conspecific.

\section{Discussion}

Collecting records indicate that most of the species are strongly or exclusively associated with fire ants in the Solenopsis saevissima species group (excepting $K$. carinatus for which no ecological data is available). Most specimens appear to have been washed out of host mounds, and there have been no reported observations of any behavioral 
interactions of the Kaszabister beetles and their hosts. As all known histerids are predaceous (Kovarik and Caterino 2005), there can be little doubt that the beetles prey on their hosts, probably the larvae and pupae. From some focused collecting it appears that the density of these beetles can be relatively high, and it's conceivable that they provide a significant level of natural control of fire ant populations. Significant interest and resources have focused on introduction of parasitic flies as natural enemies of invasive fire ants in the United States (Callcott et al. 2011). None, to our knowledge, has considered predaceous myrmecophilous beetles. It should also be noted here that, although not as common a host as Eciton Latreille, Solenopsis does host other neotropical histerid genera, including Hippeutister Reichensperger and Procolonides Reichensperger (Helava et al. 1985, Kovarik and Caterino 2005, Caterino and Tishechkin 2008).

Myrmecophily is a common phenomenon in Histeridae, with two entire large subfamilies (Haeteriinae and Chlamydopsinae) composed almost entirely of myrmecophiles (Kovarik and Caterino 2005). Outside these major groups, however, there have been numerous independent acquisitions of myrmecophilous habits in nearly all other major taxa. In Exosternini myrmecophily has arisen in both Old and New World genera, including Paratropus Gerstaecker, Coelocraera Marseul, Phelister Marseul, Pseudister Bickhardt and Tribalister Horn. Specialized myrmecophily is often associated with a suite of morphological specializations (Helava et al. 1985, Kovarik and Caterino 2005). Of these, only exaggerated striae/carinae (frontal, pronotal, elytral) present themselves in Kaszabister.

Kaszabister exhibits a largely disjunct distribution, with very few records from a large area of northern South America. At this point it seems most likely that this relates to sampling effort. The vast majority of existing specimens have resulted from direct sampling of Solenopsis colonies, which has generally been focused on those areas with species that have become invasive elsewhere, primarily in southern Brazil. At the same time, fairly intensive passive trapping (flight intercept trapping and pitfall trapping) in some of these areas has resulted in no specimens (Vaz-de-Mello unpublished data, Flechtmann unpublished data). So although other parts of South America have seen significant trapping, by ourselves and others, there has been relatively little effort to collect in the appropriate ant colonies. So it remains to be seen whether Kaszabister is really more widespread but undetected in South America. This situation is very similar to that of Hippeutister (Histeridae: Haeteriinae), with species known from Central America and southern Brazil (Caterino and Tishechkin 2008). Dedicated collecting efforts in Solenopsis nests elsewhere may well turn up additional species in both these groups.

An extensive collecting of Kaszabister in host ant colonies in 1972 in Mato Grosso has revealed some interesting facts about sympatry and syntopy of its species. Out of nine localities where $K$. barrigai was collected, at six $K$. ferrugineus was also found. Moreover, collecting colony codes reveal that both species have been collected in the same nests at Cáceres, Cuiabá, Mato Grosso Co., and Poconé. At the six localitites where both species were found $K$. barrigai was much more common, outnumbering $K$. ferrugineus by 100 to eight specimens. The situation at another locality, Arenapolis, was completely reversed: 23 specimens of $K$. ferrugineus were found in three nests there but no $K$. barrigai specimens are known from that site. Although nothing else known about 
this remarkable syntopy, the abundance patterns are suggestive of either interspecific competition, or very fine habitat and/or host preferences. Kaszabister ferrugineus and $K$. rubellus are also known to co-occur in at least one location; both were collected at Rosas, Argentina, represented by seven and six specimens, respectively. However, due to poor labeling, it is unclear whether they coexist microsympatrically or simultaneously, e.g. in the same colony or at the same time. This would be interesting to explore further.

The phylogenetic position of Kaszabister within Exosternini has never been addressed. Ongoing analyses suggest a relationship with another inquilinous and enigmatic genus, Mecistostethus Marseul, together as sister or near sister to the large genus Operclipygus Marseul. However, some of the morphological characters these share may be convergences related to myrmecophily. Final analyses remain ongoing, and a confident result with respect to Kaszabister will probably have to await the availability of molecular sequence data.

\section{Acknowledgments}

We thank the many colleagues who provided specimens, and those who hosted us during visits to their institutions: Max Barclay and Roger Booth (BMNH), Piet Kanaar (CHPK), Kiniti Kitayama (DBIA), Cheryl Barr (EMEC), Margaret Thayer, Al Newton, and James Boone (FMNH), Paul Skelley (FSCA), Angel Solís (INBI), Arturo Roig Alsina (MACN), Thierry Dueve and Azadeh Taghavian (MNHN), Gary Hevel (NMNH), Olaf Jäger (SMTD), and Manfred Uhlig and Bernd Jäger (ZHMB). We would especially like to thank Ottó Merkl (HNHM) for his assistance clarifying the status of K. mahunkai. Although no Kaszabister were found, M. Caterino and A. Tishechkin would also like to thank Fernando Vaz-de-Mello and his students, Lúcia Massutti de Almeida, Fernando Leivas, Daniel Moura, Paschoal Grossi, and Kleber Mise for assisting in the search during our fieldwork in Brazil. This project was supported in part by National Science Foundation grant DEB 0949790 to MSC and AKT.

\section{References}

Allen GE, Buren WF, Williams RN, de Menezes M, Whitcomb, WH (1974) The red imported fire ant, Solenopsis invicta: distribution and habitat in Mato Grosso, Brazil. Annals of the Entomological Society of America 67: 43-46.

Bruch C (1914) Catálogo sistemático de los Coleópteros de la República Argentina. Pars III. Revista del Museo de La Plata [ser. 2(6)] 19: 303-339.

Bruch C (1935) Suplemento al catálogo sistemático de los Coleópteros de la República Argentina. V (Addenda, corrigenda y lista de especies). Physis 11: 384-392.

Buren WF, Allen GE, Whitcomb WH, Lennartz FE, Williams RN (1974) Zoogeography of the imported fire ants. Journal of the New York Entomololgical Society 82: 113-124. 
Callcott AA, Porter SD, Weeks RD, Graham LCF, Johnson SJ, Gilbert LE (2011) Fire ant decapitating fly cooperative release programs (1994-2008): Two Pseudacteon species, $P$. tricuspis and P. curvatus, rapidly expand across imported fire ant populations in the southeastern United States. Journal of Insect Science 11(19): 1-25. doi: 10.1673/031.011.0119

Caterino MS, Tishechkin AK (2008) A review of Hippeutister Reichensperger with new species from California and Costa Rica. Zootaxa 1895: 39-52.

Erichson WF (1834) Uebersicht der Histeroides der Sammlung. Jahrbuch der Insekten-Kunde 1: 83-208.

Helava JVT, Howden HF, Ritchie AJ (1985) A review of the new world genera of the myrmecophilous and termitophilous subfamily Hetaeriinae (Coleoptera: Histeridae). Sociobiology, 10(2): 127-382.

Hölldobler B, Wilson EO (1990) The Ants. Cambridge, Massachusetts, Belknap Press of Harvard University Press, $732 \mathrm{pp}$.

Kirsch T (1873) Beiträge zur Kenntniss der peruanischen Käferfauna auf Dr. Abenroth's Sammlungen basiert. Berliner Entomologische Zeitschrift 17: 121-152.

Kovarik PW, Caterino MS (2005) Histeridae. In: Beutel RG, Leschen RAB (Eds) Handbook of Zoology Part 38, Coleoptera, Vol. 1: Morphology and Systematics. Walter de Gruyter, Berlin, 190-222.

Lawrence JF, Ślipiński A, Seago AE, Thayer MK, Newton AF, Marvaldi AE (2011) Phylogeny of the Coleoptera based on morphological characters of adults and larvae. Annales Zoologici 61(1): 1-217. doi: 10.3161/000345411X576725

Lewis G (1888) Fam. Histeridae. In: Biologia Centrali-Americana. Insecta. Coleoptera, London, 182-244.

Mazur S (1972) The scientific results of the Hungarian soil zoological expeditions to South America. 22. The species of the family Histeridae (Coleoptera). Annales Historico-Naturales Musei nationalis Hungarici 64: 183-190.

Mazur S (1984) A World Catalogue of Histeridae. Polskie Pismo Entomologiczne 54: 1-379.

Mazur S (1997) A world catalogue of the Histeridae (Coleoptera: Histeroidea). Genus International Journal of invertebrate Taxonomy, supplement: 1-373.

Ôhara M (1994) A revision of the superfamily Histeroidea of Japan (Coleoptera). Insecta Matsumurana, New Series 51: 1-283.

Wenzel RL, Dybas HS (1941) New and little known neotropical Histeridae (Coleoptera). Fieldiana, Zoology 22(7): 433-472. 